\title{
Effect of Solar Radiation on Severity of Soybean Rust
}

\author{
Heather M. Young, Sheeja George, Dario F. Narváez, Pratibha Srivastava, \\ Andrew C. Schuerger, David L. Wright, and James J. Marois
}

First, second, fourth, sixth, and seventh authors: University of Florida-NFREC, Quincy 32351; third author: Monsanto, St. Louis, MO 63137; fifth author: University of Florida, Building M6-1025, Space Life Sciences Laboratory, Kennedy Space Center, FL 32899. Accepted for publication 20 April 2012.

\section{ABSTRACT}

Young, H. M., George, S., Narváez, D. F., Srivastava, P., Schuerger, A. C., Wright, D. L., and Marois, J. J. 2012. Effect of solar radiation on disease severity of soybean rust. Phytopathology 102:794-803.

Soybean rust (SBR), caused by Phakopsora pachyrhizi, is a damaging fungal disease of soybean (Glycine max). Although solar radiation can reduce SBR urediniospore survival, limited information is available on how solar radiation affects SBR progress within soybean canopies. Such information can aid in developing accurate SBR prediction models. To manipulate light penetration into soybean canopies, structures of shade cloth attenuating 30,40 , and $60 \%$ sunlight were constructed over soybean plots. In each plot, weekly evaluations of severity in lower, middle, and upper canopies, and daily temperature and relative humidity were recorded. Final plant height and leaf area index were also recorded for each plot. The correlation between amount of epicuticular wax and susceptibility of leaves in the lower, middle, and upper canopies was assessed with a detached leaf assay. Final disease severity was 46 to $150 \%$ greater in the lower canopy of all plots and in the middle canopy of 40 and $60 \%$ shaded plots. While daytime temperature within the canopy of nonshaded soybean was greater than shaded soybean by 2 to $3^{\circ} \mathrm{C}$, temperatures recorded throughout typical evenings and mornings of the growing season in all treatments were within the range $\left(10\right.$ to $\left.28.5^{\circ} \mathrm{C}\right)$ for SBR development as was relative humidity. This indicates temperature and relative humidity were not limiting factors in this experiment. Epicuticular wax and disease severity in detached leaf assays from the upper canopy had significant negative correlation $(P=0.009, R=-0.84)$ regardless of shade treatment. In laboratory experiments, increasing simulated total solar radiation (UVA, UVB, and PAR) from 0.15 to $11.66 \mathrm{MJ} \mathrm{m}^{-2}$ increased mortality of urediniospores from 2 to $91 \%$. Variability in disease development across canopy heights in early planted soybean may be attributed to the effects of solar radiation not only on urediniospore viability, but also on plant height, leaf area index, and epicuticular wax, which influence disease development of SBR. These results provide an understanding of the effect solar radiation has on the progression of SBR within the soybean canopy.
Soybean rust (SBR), caused by Phakopsora pachyrhizi Syd. and P. Syd., has the potential to be a damaging fungal disease of soybean (Glycine max (L.) Merr). SBR often is first detected in low light environments and regularly progresses from the lower to upper soybean canopy. Favorable meteorological and environmental conditions such as temperature, relative humidity and rainy days with prolonged cloudiness are critical components that affect the progress of disease development (11).

Identification and quantification of the key factors that drive an SBR epidemic are critical components for assessing and managing SBR risks. Such studies provide a rational basis to improving disease management and subsequently preventing yield loss. There is very little quantitative information on the effect of environmental and meteorological conditions in the field when compared with the body of literature from growth chamber and greenhouse studies.

Since long-distance dispersal of SBR urediniospores has been confirmed (21), there has been a surge in new epidemiological studies for SBR to accurately predict and manage the disease across a large geographical area. As a consequence, several disease models have been developed that integrate meteorological data such as wind speed, wind direction, and solar radiation as predictors to assess the risk of the disease at various geographical scales $(12,18,28)$.

While airborne, the survival of fungal spores is affected by temperature, solar radiation, ultraviolet radiation, and relative

Corresponding author: H. M. Young; E-mail address: hmarieyoung@ufl.edu

http://dx.doi.org/10.1094/PHYTO-10-11-0294

(C) 2012 The American Phytopathological Society humidity (18). Pathogenicity of fungal spores, in the course of long-distance aerial spread, is dependent upon spore susceptibility to variation in temperature, relative humidity, and solar radiation over the time that they are suspended in the atmosphere and after deposition before penetration. Solar radiation has been demonstrated to have the potential to increase canopy temperature, reduce relative humidity, and reduce SBR urediniospore survival (18), but limited field information is available on how solar radiation triggers physiological changes in the structure of the soybean plant canopy, which might also influence SBR development. This information could be another important factor for accurate predictions using aerobiological models for SBR forecasting $(18,28)$.

Components of solar radiation (UVB radiation; 280 to $320 \mathrm{~nm}$ ) can affect crop growth directly through photosynthesis and photomorphogenic systems, up regulation of pathways producing defense compounds (e.g., flavonoids and related phenolic compounds or waxes), decreased vegetative growth, and decreased developmental times. In contrast, the UVB (280 to $320 \mathrm{~nm}$ ) component of solar radiation also has a range of effects on invading pathogens that include damage to DNA and proteins thus affecting metabolic and physiologic responses of the organism (1). Ghajar et al. (15) and Rotem and Aust (29) reported that UV radiation in sunlight, and not temperature, are the major factor affecting germination of fungal propagules. The extent of damage caused by biotic factors (pest, pathogens, and weeds) on growth and development of crop plants can be modified by abiotic factors such as solar radiation, possibly making the plants more or less susceptible to pest pressure (19).

Soybean leaves from canopies exposed to solar UVB showed significantly higher levels of soluble phenolics and lower levels of 
lignin than leaves that developed in canopies covered by polyester films (39). Canopy shading can reduce solar radiation and impact the microclimate affecting plant physiology including cuticular wax. Experimental and observational data reports show that high radiant energy, low humidity, and higher temperatures (23 to $30^{\circ} \mathrm{C}$ ) are favorable conditions for maximum wax production $(4,10,32)$. Once the canopy closure is $100 \%$, creating a completely shaded area between rows, the entire exposed upper canopy begins to act as a more uniform evaporative surface diminishing the differences in shading of the soil surface and variation in heat from soil between rows due to reflection of radiation (33).

Recently, the effects of sunlight (both total solar and ultraviolet radiation) on urediniospore survival have been used to predict $P$. pachyrhizi urediniospore germination (17). The recommendations, based on the findings of Isard et al. (17), have been included in the U.S. Department of Agriculture's aerobiological model for SBR epidemiology. While field experiments on influence of total solar radiation on $P$. pachyrhizi urediniospore germination have been conducted by Isard et al. (17), these factors have not been studied under laboratory conditions in the absence of other environmental parameters that may otherwise confound the correlation between them and urediniospore survival and viability. The objectives of this study were to investigate the effect of solar radiation on progress of SBR in the field and to evaluate the effect of exposure of $P$. pachyrhizi urediniospores to varying intensities of simulated solar radiation on spore viability under laboratory conditions.

\section{MATERIALS AND METHODS}

Canopy manipulation. To investigate the effect of solar radiation on the progress of SBR, four soybean plantings were established at the North Florida Research and Education Center (NFREC) in Quincy, Florida. Early plantings occurred on 11 April 2008 and 24 April 2009 and late plantings on 4 August 2008 and 23 July 2009; henceforth designated as early or late plantings, respectively. All plantings were in the same field. Asgrow cultivar 5905 Roundup Ready, maturity group 5 soybeans were planted on $76 \mathrm{~cm}$ rows, over a total area of $15,600 \mathrm{~m}^{2}$, on average. Three structures $\left(3 \times 3 \mathrm{~m}^{2}\right)$ of black knitted shade cloth (Rimol Greenhouse Systems, Inc. Hooksett, NH) were constructed at least $4.6 \mathrm{~m}$ apart from each other and had a minimum of $4.6 \mathrm{~m}$ soybean boundary around the perimeter. Control plots with the same area and parameters but without shade cloth were also established. The shade cloth attenuated 30,40 , or $60 \%$ sunlight as stated by the manufacturer and also determined by using an Optronic OL754 spectroradiometer (Optronic Inc., Orlando, FL) (Table 1). Each shade treatment was replicated three times for a total of 12 plots. The shade cloth structures were constructed over the soybeans at vegetative growth stage V3 to V4 (25) in a complete randomized block design. Subsequently, leaves were marked on three individual plants in each plot, starting at growth stage V3, to be utilized for leaf assays.

Plant height was measured at reproductive growth stage R3 in the early and late planting of 2008 in all treatments. At reproductive growth stage $\mathrm{R} 3$ there is little to no further increase in height in determinant soybeans and hence this stage was chosen to measure the overall effect the treatments had on plant height. Data log tags (MicroDAQ.com, Ltd., Contoocook, NH) were used to record temperature and relative humidity every $20 \mathrm{~min}$ in the middle of each plot at approximately $36 \mathrm{~cm}$ above the soil for the duration of the experiment. The weeks during reproductive growth stage R3 to R4 (pod growth) of each planting were selected as typical examples of temperature and relative humidity observed throughout the growing season and critical time periods for disease development. Leaf area indices (LAI) were obtained for early and late plantings of soybeans in 2008 on 9 July and 3 October at reproductive growth stage R3 and for the late planting in 2009 on 11 October at reproductive growth stage R6 by measuring photosynthetically active radiation (PAR; 400 to $700 \mathrm{~nm}$ ) approximately 10 to $20 \mathrm{~cm}$ above the top of the canopy, but under the shade cloth, and 25 to $30 \mathrm{~cm}$ below the top of the canopy using a LI-COR 191 quantum sensor and LI-1400 Data Logger (LI-COR Biosciences, Lincoln, NE). All measurements were taken between 11:00 AM and 2:00 PM (EDT) (UTC 16:00 to 19:00). The following equation was used to calculate LAI from the PAR values: $\mathrm{LAI}=-(1 / k) \ln \left(Q_{b} / Q_{a}\right)(37)$, where $Q_{a}$ is the above canopy PAR, and $Q_{b}$ is the below canopy PAR. The extinction coefficient, $k$, of 0.4 was used based on Flenet et al. (14). Average light transmissions at the upper soybean canopies in plots covered by the 30,40 , and $60 \%$ shade cloth were measured using an Optronic OL754 spectroradiometer (Optronic Inc.) measuring energy values $\left(\mathrm{W} \mathrm{m}^{-2}\right.$ ) between 270 and $775 \mathrm{~nm}$ (Table 1). All light transmission measurements were taken on 28 September 2009. Similar measurements were also made in the lower, middle, and upper canopies of control plots (Table 2). The lower, middle, and upper canopy represented plant area from nodes 1 to 3,3 to 6 , and 6 to 10 , respectively. In terms of plant height, the lower, middle, and upper canopy for early plantings corresponded to plant area between 10 and $30 \mathrm{~cm}, 30$ to $60 \mathrm{~cm}$, and 60 to $100 \mathrm{~cm}$ from the ground, while for the late plantings, these corresponded to plant area between 10 to $20 \mathrm{~cm}, 20$ to $40 \mathrm{~cm}$, and 40 to $70 \mathrm{~cm}$ from the ground, respectively.

Field inoculations and evaluations. Urediniospores used for inoculation were collected the previous week from soybeans (Asgrow cultivar 5905 Roundup Ready, maturity group 5) infected with a population of urediniospores collected the previous year from naturally infected soybean at the North Florida Research and Education Center in Quincy, Florida. Diseased plants were maintained in a greenhouse and urediniospores were collected using a cyclone spore collector (G-R Manufacturing Co., Manhattan, KS) from the underside of infected leaves and stored in a 10 -ml glass vial at $-20^{\circ} \mathrm{C}$ until spore suspension was made.

TABLE 1. Energy values $\left(\mathrm{W} \mathrm{m}^{-2}\right.$ ) recorded in 0, 30, 40, and 60\% shaded soybean plots on 28 September 2009 at the North Florida Research and Education Center in Quincy, Florida

\begin{tabular}{|c|c|c|c|c|c|c|}
\hline \multirow[b]{2}{*}{ Shade treatment $(\%)$} & \multicolumn{2}{|c|}{$\mathrm{UVB}^{\mathrm{ab}}$} & \multicolumn{2}{|c|}{$\mathrm{UVA}^{\mathrm{ac}}$} & \multicolumn{2}{|c|}{ PAR $^{\text {ad }}$} \\
\hline & $\mathrm{W} \mathrm{m}^{-2}$ & $\begin{array}{l}\text { Percent of radiation } \\
\text { relative to full sunlight }\end{array}$ & $\mathrm{W} \mathrm{m}^{-2}$ & $\begin{array}{l}\text { Percent of radiation } \\
\text { relative to full sunlight }\end{array}$ & $\mathrm{W} \mathrm{m}^{-2}$ & $\begin{array}{l}\text { Percent of radiation } \\
\text { relative to full sunlight }\end{array}$ \\
\hline 0 & 3.37 & 100 & 47.53 & 100 & 349.2 & 100 \\
\hline 40 & 1.84 & 55 & 24.66 & 52 & 173.7 & 50 \\
\hline 60 & 1.23 & 36 & 16.22 & 34 & 111.9 & 32 \\
\hline
\end{tabular}

a First columns for each UV band is the $\mathrm{W} \mathrm{m}^{-2}$ recorded using an Optronic OL754 spectroradiometer (Optronic Inc., Orlando, FL) measuring energy values between 270 and $775 \mathrm{~nm}$. Second columns of each UV band represent the UV flux relative to the upper canopy in the full sun (nonshaded) soybeans.

${ }^{\text {b }}$ UVB, ultraviolet radiation at 300 to $320 \mathrm{~nm}$.

c UVA, ultraviolet radiation at 320 to $400 \mathrm{~nm}$.

d PAR, photosynthetically active radiation at 400 to $700 \mathrm{~nm}$. 
The early plantings of 2008 and 2009 were inoculated at growth stage R1 with a suspension of approximately 75,000 urediniospores per $\mathrm{ml}$ of water and $10 \mu \mathrm{l}$ of Tween 20 between 6 and 8 P.M. Eastern Standard Time. Inoculations were conducted in the evening to ensure all plots were exposed to similar environmental conditions for inoculation and to enhance probability of infection. Late plantings were naturally infected with SBR with no addition of inoculum. Germination of urediniospores was assessed by plating $100 \mu \mathrm{l}$ of urediniospore suspension on $1 \%$ water agar and recording the number of germinated urediniospores out of 100. A spore was considered germinated if the germ tube was twice as long as the spore's length. Approximately 0.5 liters of the spore suspension was applied to the lower canopy in each plot using a hand-held spray bottle to simulate a natural SBR infection, which usually develop in the lower canopy. Weekly evaluations were made, starting 10 to 14 days after inoculation for early plantings or for late plantings at growth stage R1 (flowering) because natural SBR infection usually occurs at the beginning of soybean reproductive stages. Ten randomly preassigned areas in each plot were evaluated at the lower, middle, and upper canopies, as previously described, for severity of SBR based on visual assessment of symptomatic leaf area using the scale $0=$ no disease, $1=$ up to $2.5 \%, 2=2.5$ to $5 \%, 3=5$ to $10 \%, 4=10$ to $15 \%, 5=15$ to $25 \%, 6=25$ to $35 \%, 7=35$ to $67.5 \%$, and $8=67.5$ to $100 \%$ of the leaf area affected by SBR. Average severity rating was determined by converting each rating to the midpoint of its range, i.e., $0=0 \%, 1=1.25 \%, 2=3.75 \%, 3=7.5 \%, 4=12.5 \%, 5=$ $20 \%, 6=30 \%, 7=51.25 \%$, and $8=83.75 \%$ (38).

Detached leaf assays. At growth stage R1 (flowering) (25), two premarked leaflets each from the lower, middle, and upper canopies, as previously described, were collected for leaf assays to assess the amount of epicuticular wax and susceptibility of leaves to SBR. An additional leaflet was collected from the lower canopy of each plot to verify SBR was not present in the field at that time. The detached leaflets were rinsed with sterile distilled water and allowed to dry. One set of leaflets was immediately used to assess susceptibility and the other set was placed in resealable plastic bags and placed at $-20^{\circ} \mathrm{C}$ for future analysis of epicuticular wax. Leaflets collected from both early plantings and the late planting in 2008 were used in susceptibility assays and leaflets from the early planting in 2009 and both late plantings were used in epicuticular wax assays.

For the susceptibility assay the detached leaflets were inoculated with urediniospores of $P$. pachyrhizi which were collected from diseased soybeans in a greenhouse the previous day and kept in frozen storage (approximately $-20^{\circ} \mathrm{C}$ ) until use. A suspension of 15,000 urediniospores per $\mathrm{ml}$ of water with $10 \mu \mathrm{l}$ of Tween 20 was used to inoculate the upper and lower surface of each leaflet using approximately $3 \mathrm{ml}$ of suspension per leaflet by using a KC-566CG air sprayer (Lowes, North Wilkesboro, NC). The suspension was also sprayed on a plate of $1 \%$ water agar and germination was assessed as previously described. After inoculation, the petiole of each leaflet was cut diagonally with a scalpel to produce a clean, fresh surface. Each leaflet was then placed in an individual petri plate $(150 \times 15 \mathrm{~mm})$ half-filled with $1 \%$ water agar with the petiole inserted into the agar. Petri plates were kept at room temperature (approximately $24^{\circ} \mathrm{C}$ ) and exposed to approximately $30 \%$ of natural sunlight for $8 \mathrm{~h}$ per day. Leaflets were evaluated 14 to 20 days after inoculation using the rating scale previously given. Noninoculated control leaflets from the lower canopy were also maintained in petri plates halffilled with $1 \%$ water agar and evaluated along with inoculated leaflets.

For determination of epicuticular wax, frozen leaflets were thawed 2 to 3 months after they were first sampled and stored. Epicuticular wax was measured using the following modified procedures from Beattie and Marcell (7). Individual leaflets were submerged in $10 \mathrm{ml}$ of chloroform in preweighed aluminum foil boats for $30 \mathrm{~s}$. The waxes were dried by placing the foil boats on a hotplate (approximately $150^{\circ} \mathrm{C}$ ) until chloroform had evaporated. After an hour of incubation at room temperature the foil boats were weighed. The area of each leaflet was obtained using the LICOR 3000 portable area meter with LI-COR 3000 transparent conveyer belt accessory (LI-COR Biosciences, Lincoln, NE). The amount of wax extracted from a leaflet was expressed as milligram of wax per square centimeter of leaf area.

Data analysis. Statistical analyses were performed using SAS 9.1 (Statistical Analysis Software version 9.1, SAS Institute Inc., Cary, NC). After 7 days when soybean was in reproductive growth stage R3 to R4 (pod development) the temperature and relative humidity data were averaged across repetitions at each 20-min interval they were recorded for each planting, resulting in data representing typical daily temperature and relative humidity throughout a $24 \mathrm{~h}$ period at 20 -min intervals. These data were analyzed by the general linear model procedure and Fisher's least significant difference test at a significance level of 0.05 .

Average disease severity across repetitions for each evaluation date was used to calculate the area under the disease progress curve (AUDPC) using the formula:

$$
A U D P C=\sum_{i=1}^{n} \frac{\left(x_{i+1}+x_{i}\right)}{2}\left(t_{t+1}-t_{i}\right)
$$

where $x_{i}=$ proportion of tissue affected (disease severity) at the $i$ th observation, $t=$ time (days), and $n=$ total number of observations. $\Sigma$ is the sum of areas of all of the individual trapezoids or areas from $i$ to $n-1$. $i$ and $i+1$ represent observations from 1 to $n$. AUDPC was analyzed within each canopy height for each planting by analysis of variance (ANOVA) with shade treatment as the main effect. Fisher's least significant difference test at a significant level of 0.05 was used for multiple comparisons among treatments.

Disease severity recorded at growth stage R5 was averaged across each planting date at each canopy level and shade treatment. Average disease severity from field experiments at growth stage R5, disease severity in detached leaves, and amount of epicuticular wax from detached leaves were analyzed by twofactor ANOVA with interaction. Factors used as main effects were

TABLE 2. Energy values $\left(\mathrm{W} \mathrm{m}^{-2}\right)$ recorded in nonshaded control soybean plots on 28 September 2009 at the North Florida Research and Education Center in Quincy, Florida

\begin{tabular}{|c|c|c|c|c|c|c|}
\hline \multirow[b]{2}{*}{ Canopy level } & \multicolumn{2}{|r|}{$\mathrm{UVB}^{\mathrm{ab}}$} & \multicolumn{2}{|r|}{$\mathrm{UVA}^{\mathrm{ac}}$} & \multicolumn{2}{|r|}{ PAR $^{\text {ad }}$} \\
\hline & $\mathrm{W} \mathrm{m}^{-2}$ & Percent relative to upper canopy & $\mathrm{W} \mathrm{m}^{-2}$ & Percent relative to upper canopy & $\mathrm{W} \mathrm{m}^{-2}$ & Percent relative to upper canopy \\
\hline Upper & 3.00 & 100 & 43.8 & 100 & 328.3 & 100 \\
\hline Middle & 1.19 & 40 & 10.5 & 23 & 78.7 & 23 \\
\hline
\end{tabular}

a First columns for each UV band report raw data $\left(\mathrm{W} \mathrm{m}^{-2}\right)$ recorded using an Optronic OL754 spectroradiometer (Optronic Inc., Orlando, FL) measuring energy

values between 270 to $775 \mathrm{~nm}$. Second columns of each UV band represent the UV flux relative to the upper canopy.

${ }^{b}$ UVB, ultraviolet radiation at 300 to $320 \mathrm{~nm}$.

${ }^{c}$ UVA, ultraviolet radiation at 320 to $400 \mathrm{~nm}$.

d PAR, photosynthetically active radiation at 400 to $700 \mathrm{~nm}$. 
shade treatment, canopy height, and plant date. Fisher's least significant difference test at a significant level of 0.05 was used for multiple comparisons among treatments and canopy height by means of the general linear model procedure of SAS when significant differences were found in the ANOVA table. Significant correlations were determined for disease severity and epicuticular wax, from detached leaves across shade treatments and canopy height, using Pearson's correlation test.

Simulated solar radiation lab experiment. Urediniospore collection. Soybean plants inoculated with $P$. pachyrhizi urediniospores were maintained in a greenhouse at 70 to $90 \%$ relative humidity. The plants were monitored for sporulation. Eight to 10 diseased soybean plants, in reproductive growth stage R1 to R3, were selected and tagged as a continuous source of fresh inoculum throughout the experiment. Leaves from the selected plants were washed with deionized water on the day before urediniospores were collected for the experiment to ensure uniform age of spores used in the experiment. One-day-old spores were collected the next morning by using a cyclone spore collector (G-R Manufacturing Co.) from the underside of the previously washed leaves, and transported to the laboratory in a 10 -ml glass vial.

Light source and experimental set-up. Urediniospores of $P$. pachyrhizi were exposed to simulated solar radiation of varying intensities for different time intervals to determine the effect of exposure time and intensity on reduction in viability of urediniospores. The light source was a $1000 \mathrm{~W}$ xenon-arc lamp (model 6269, Oriel/Newport Instruments, Stratford, CT). A 6-cm water filter in the light path just after the xenon arc lamp eliminated near-infrared (NIR) radiation above 1,100 nm (31). Petri plates made of glass (Thermo Fisher Scientific Inc., WI; Catalog No. 08-746C) and polystyrene (Thermo Fisher Scientific Inc.; Catalog No. 08-747-14) were placed in the light path to eliminate the UVC ( 200 to $280 \mathrm{~nm}$ ) component of radiation from the light source (A. C. Schuerger, unpublished data). Light comprising UVB (280 to $320 \mathrm{~nm}$ ) and UVA (320 to $400 \mathrm{~nm}$ ) radiation bands, and PAR (400 to $700 \mathrm{~nm}$ ) was delivered to the working surface through a focusing lens. Near-infrared (NIR) photons from 700 to $1,100 \mathrm{~nm}$ were also present in the light beam. The distance between the bottom of the focusing lens and the working surface (on which petri dishes with urediniospores were placed) was adjusted to simulate overhead sun conditions as measured in the field on 28 September 2009 at 2:00 PM at the North Florida Research and Education Center. All light calibration spectra were collected using an Optronic OL754 UV-VIS spectrometer (270 to $775 \mathrm{~nm}$ scans; Optronic Inc.). The combined UVB, UVA, and PAR fluence rates equaled $0.405 \mathrm{MJ} \mathrm{m}^{-2}\left(405.26 \mathrm{~W} \mathrm{~m}^{-2}\right)$. The UVA and UVB components of the total solar radiation ranged from 0.02 to $1.53 \mathrm{MJ} \mathrm{m}^{-2}$. Lower intensities of the simulated solar radiation to mimic in-canopy UV and PAR fluence rates were achieved by directing light from the lamp through stainless steel wire-mesh screens $\left(150 \times 150 \mathrm{~mm}^{2}\right)$ that were placed above the urediniospores. Thicknesses of the wire mesh screens were adjusted to $1.3 \mathrm{~mm}$ (three screens) and $2.7 \mathrm{~mm}$ (7 screens) to obtain 50 and $10 \%$ transmission, respectively, of the full intensity $(0.405$ $\mathrm{MJ} \mathrm{m}^{-2}$ ) of simulated solar radiation.

Exposure of urediniospores to simulated solar radiation. Urediniospores were sieved through a single layer of cheese cloth to remove debris and disperse urediniospore clumps. Approximately 100 dry urediniospores were transferred onto premarked arc-shaped areas on $24 \times 50 \mathrm{~mm}^{2}$ polystyrene coated coverslips by lightly touching the bottom of the cheesecloth on the marked areas. The coverslips with urediniospores were arranged in a $100 \mathrm{~mm}$ petri dish and placed in the light path such that marked areas of all the coverslips were uniformly irradiated. Exposure was performed at room temperature (approximately $24^{\circ} \mathrm{C}$ ) in the laboratory. Temperature throughout the experiment was constant and care was taken to avoid overheating. An identical assembly of urediniospore laden coverslips, placed in a petri dish covered with aluminum foil to block all light and kept at room temperature served as the control for this experiment. One coverslip each, from the control set and the radiated set, were removed at the end of $1,2,3,4,5,6,7$, and $8 \mathrm{~h}$. As soon as the coverslips were removed, they were moistened with a uniform spray of water dispensed from a pre-val sprayer (Precision Valve Corporation, Yonkers, NY), placed in a petri plate lined with moist paper towels, and incubated for $4 \mathrm{~h}$ under normal laboratory conditions to facilitate urediniospore germination. After $4 \mathrm{~h}$ the urediniospores were stained with 2 drops of lactophenol blue (8) and observed under a light microscope at $10 \times$ magnification. At the start of each series of exposure, urediniospores were dusted on a coverslip and immediately moistened, incubated, and treated as described above. This served as the unexposed control $(0 \mathrm{~h})$ to account for daily variability in germinability of $P$. pachyrhizi spores. The number of urediniospores out of 100 that did not germinate, formed germ tubes only, and formed germ tubes and appressoria were enumerated and standardized to the $0 \mathrm{~h}$ control. Percentage germination and appressoria formation in radiated and nonradiated urediniospores were calculated. All experiments were conducted twice.

\section{RESULTS}

Canopy manipulation. At growth stage R3, in the early planting (11 April) of 2008, shade treatment did not significantly affect plant height $(P=0.412, F=1.08)$. Whereas in the late planting (4 August) of 2008, shade treatment significantly affected plant height $(P=0.004, F=10.18)$, where plant height under 40 and $60 \%$ shade were significantly greater than those under 0 and $30 \%$ shade (Fig. 1). Furthermore, plant height from the early planting of 2008 was significantly greater than plant height from the late planting of 2008. LAI were significantly affected by plant date $(P<0.0001, F=26.73)$. Where LAI from the early planting of 2008, with the exception of LAI from $60 \%$ shaded soybean, were significantly greater than LAI from the late plantings in 2008 and 2009 (Fig. 2). There were no significant differences in LAI across treatments in the late planting of 2008; however LAI from nonshaded and $30 \%$ shaded treatments of the 2009 planting had significantly greater LAI than those from 40 and $60 \%$ shaded treatments. The two-way ANOVA of disease severity at reproductive stage $\mathrm{R} 5$ showed a significant effect of the shade treatments $(F=20.37, P=0.0001)$ and canopy height $(F=128.44, P<0.0001)$, but not of their interaction $(F=$ 2.28, $P=0.088$ ) (Table 3). Plant date, as expected, also had a

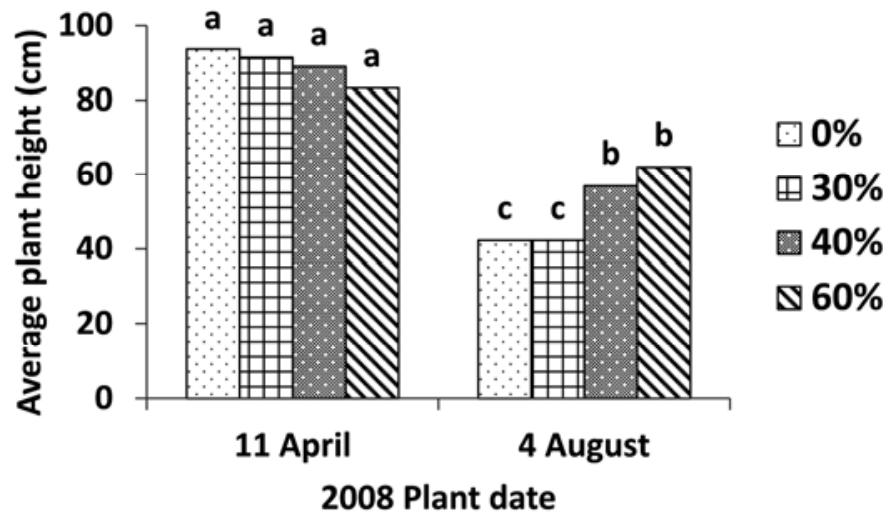

Fig. 1. Average plant height $(\mathrm{cm})$ at growth stage R3 for early (11 April) and late (4 August) planted soybeans in 2008, under 0,30, 40, and 60\% shade treatment installed at growth stage V3-V4. Different letters on the bars indicate significant differences between early and late planting dates and among treatments based on averages analyzed by least significant differences at $P \leq 0.05$. 
significant effect $(F=8.06, P=0.002)$ as well as its interaction with shade treatment $(F=4.26, P=0.009)$.

Temperature was significantly affected by shade treatments $(F=8.80, P<0.0001)$, although only temperature in the nonshaded treatment was significantly greater than the shaded treatments by 2 to $3^{\circ} \mathrm{C}$, with regard to maximum temperature recorded (Fig. 3). Temperatures ranged from 20 to $30^{\circ} \mathrm{C}$ throughout typical days of the growing season, with morning and evening temperatures from 10 to $28.5^{\circ} \mathrm{C}$. Relative humidity was not significantly affected by shade treatments $(F=2.00, P=0.11)$ and ranged from 76 to $100 \%$ throughout typical days of the growing season and had an average of $93 \%$ across all treatments. UVB, UVA, and PAR values, when converted to a percentage of the upper canopy energy values, were affected approximately in proportion to the percent shade (Fig. 4; Table 1).

Field inoculations and evaluations. In both inoculated and naturally infected plots, disease was first detected in the lower canopy and progressed upwards (Fig. 5). AUDPC was significantly affected by shade treatment in both 2008 plantings, where nonshaded and $30 \%$ shaded plots had significantly lower

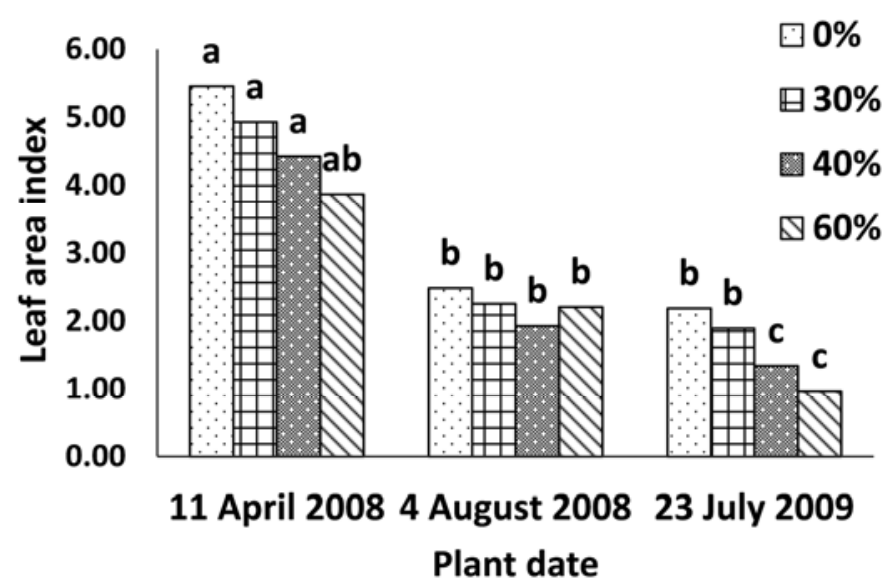

Fig. 2. Average leaf area indices measured at reproductive growth stage R 3 for early (11 April) and late (4 August) planted soybeans on 9 July 2008 and 3 October 2008, respectively; and at reproductive growth stage R6 for late (23 July) planted soybeans on 11 October 2009 under 0,30 , 40, or $60 \%$ shade installed at growth stage V3 to V4. Leaf area indices were measured using LICOR 191 quantum sensor and LI-1400 Data Logger (LI-COR Biosciences; Lincoln, NE). Different letters on the bars indicate significant differences between planting dates and among shade treatments based on averages analyzed by least significant differences at $P \leq 0.05$.
AUDPC in the middle and upper canopies. AUDPC was not significantly affected by shade treatment in the late 2009 planting. Final disease severity, recorded at growth stage R5, was significantly greater in the lower canopy of all treatments and in the middle canopy of 40 and $60 \%$ shade treatments (Fig. 6). In the middle canopy, the final disease severity in the nonshaded and $30 \%$ shade treatments were significantly lower than the 40 and $60 \%$ shade treatments. In the upper canopy, the final disease severity in the 40 and $60 \%$ shade treatments were significantly greater than the nonshaded treatments.

Detached leaf assays. Similar to severity results from the field, the greatest disease severity was observed on leaves collected from the lower canopy of all treatments (Fig. 7). Leaflets
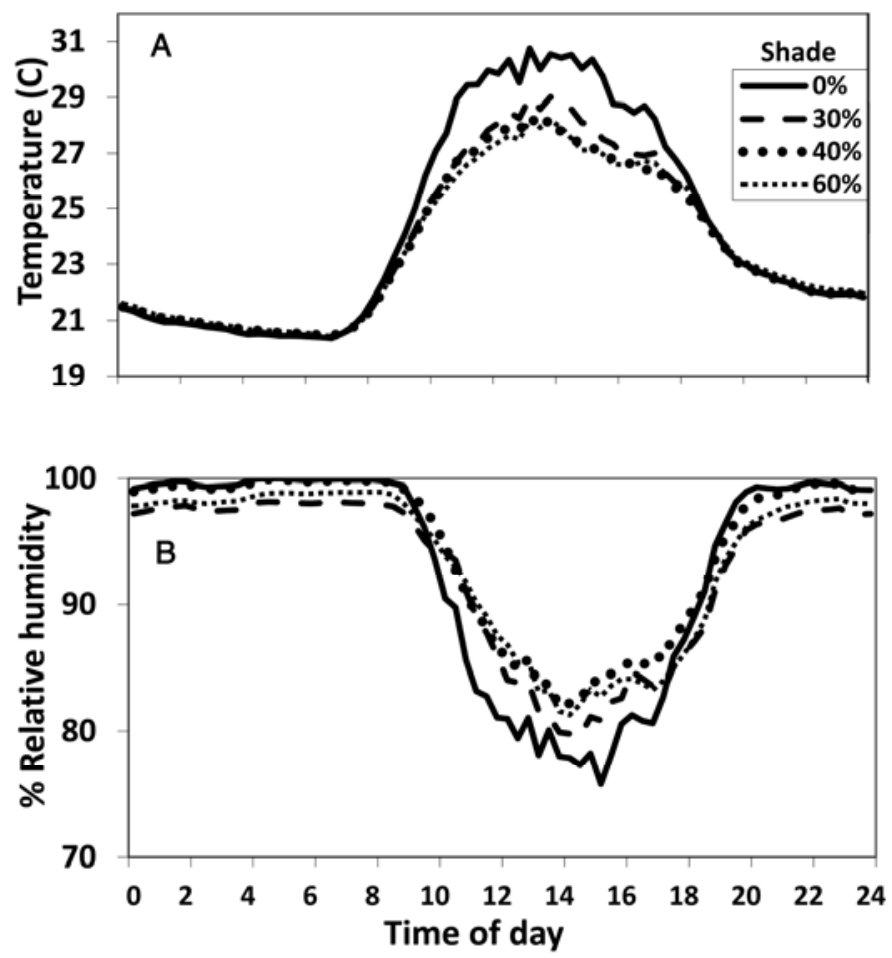

Fig. 3. A, Ambient temperature and B, relative humidity were recorded approximately $36 \mathrm{~cm}$ above the soil (mid-canopy) within soybean rows. Temperature and relative humidity were recorded every $20 \mathrm{~min}$ in soybeans grown under nonshaded, 30, 40, or $60 \%$ shade material installed at vegetative growth stage (V3 to V4).

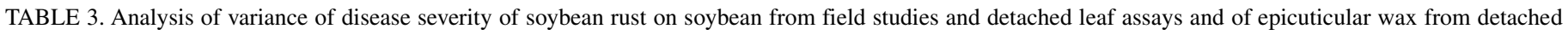

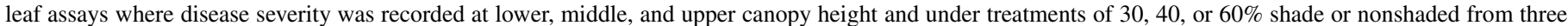
planting dates

\begin{tabular}{|c|c|c|c|}
\hline Effect & Degrees of freedom & $F$ value & $P$ value \\
\hline \multicolumn{4}{|l|}{ Disease severity from field studies } \\
\hline Shade treatment & 3 & 20.37 & $<0.0001$ \\
\hline Canopy height & 2 & 128.44 & $<0.0001$ \\
\hline Planting date & 2 & 8.06 & 0.0024 \\
\hline Shade treatment $\times$ canopy height & 6 & 2.28 & 0.0875 \\
\hline Shade treatment $\times$ planting date & 6 & 4.26 & 0.0094 \\
\hline \multicolumn{4}{|c|}{ Disease severity from detached leaf assays } \\
\hline Shade treatment & 3 & 3.64 & 0.0158 \\
\hline Canopy height & 2 & 36.14 & $<0.0001$ \\
\hline Planting date & 2 & 11.97 & $<0.0001$ \\
\hline Shade treatment $\times$ canopy height & 6 & 0.27 & 0.9503 \\
\hline Shade treatment $\times$ planting date & 6 & 0.70 & 0.6494 \\
\hline \multicolumn{4}{|c|}{ Epicuticular wax from detached leaf assays } \\
\hline Shade treatment & 3 & 5.98 & 0.001 \\
\hline Canopy height & 2 & 2.53 & 0.0857 \\
\hline Planting date & 2 & 27.30 & $<0.0001$ \\
\hline Shade treatment $\times$ canopy height & 6 & 0.41 & 0.8678 \\
\hline Shade treatment $\times$ planting date & 6 & 0.44 & 0.8475 \\
\hline
\end{tabular}


collected and used as controls to verify SBR was not present in the field at the time of collection did not develop any signs or symptoms of SBR (data not shown). Disease severity on leaves collected from the lower canopy was significantly greater than severities observed on leaves from the upper canopy within the same treatment. Similar to the results from the two-way ANOVA of disease severity from the field studies, a significant effect of

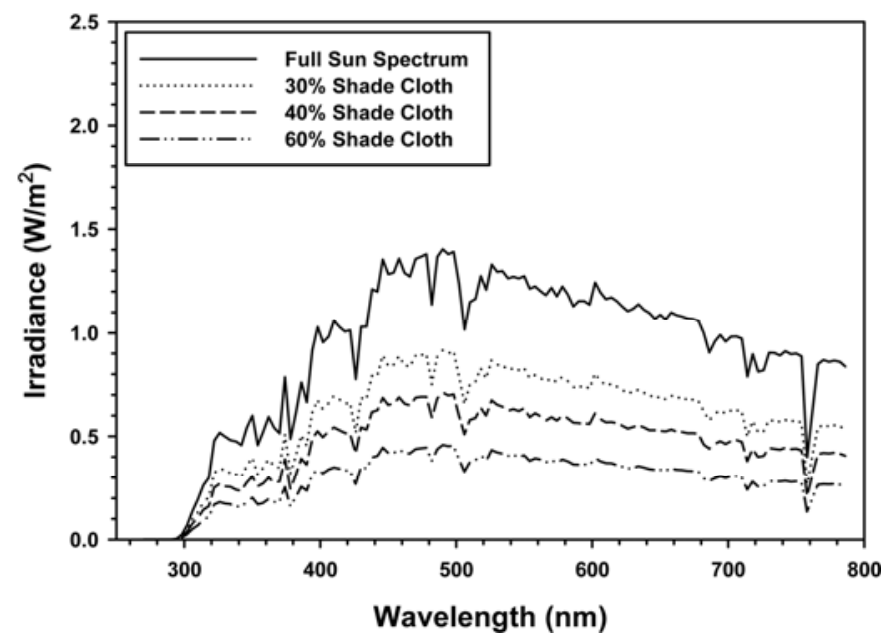

Fig. 4. Comparative ultraviolet-visible solar spectrum $(270$ to $775 \mathrm{~nm})$ of overhead sun at 2:00 PM EDT measured under the 0,30, 40, and 60\% shade plot treatments on 28 September, 2009. The spectrum was obtained using an Optronic OL754 spectroradiometer (Optronic Inc., Orlando, FL). plant date $(F=11.97, P<0.0001)$, shade treatment $(F=3.64$, $P=0.016)$, and canopy height $(F=36.14, P<0.0001)$ was observed for disease severity on detached leaves. The interaction of shade treatment and canopy height $(F=0.27, P=0.948)$ and shade treatment and plant date $(F=0.7, P=0.649)$ were not significant (Table 3).

Amounts of epicuticular wax from leaves in upper canopies in nonshaded treatments were significantly greater than all other shade treatments at all canopy heights, with the exception of wax from the upper canopy in 30\% shaded treatments (Fig. 8). The amount of epicuticular wax was not significantly different among treatments at the lower and middle canopies. Furthermore, the amount of epicuticular wax from the upper canopies in the 40 and $60 \%$ shaded treatments were not significantly different than amounts from the lower and middle canopies. However, epicuticular wax and disease severity had significant negative correlation $(P=0.009, R=0.84)$ in the upper canopy, regardless of shade treatment. The two-way ANOVA of epicuticular wax from detached leaves showed a significant effect of plant date $(F=27.3, P<0.0001)$ and shade treatment $(F=5.98, P=0.001)$ but not for canopy height $(F=2.53, P=0.086)$. Similar to the results on severity from the detached leaf assay both interactions of shade treatment and canopy height $(F=0.41, P=0.868)$ and shade treatment and plant date $(F=0.44, P=0.848)$ were not significant (Table 3 ).

Simulated solar radiation lab experiment. The percent survival of urediniospores decreased linearly as the simulated solar irradiance flux increased. A linear regression model was fit to the data; $y=-0.0704(x)+0.9065 ; P<0.05 ; R^{2}=0.69$ (Fig. 9). No loss of viability was observed in unexposed urediniospores over the duration of the experiment. As the simulated total solar

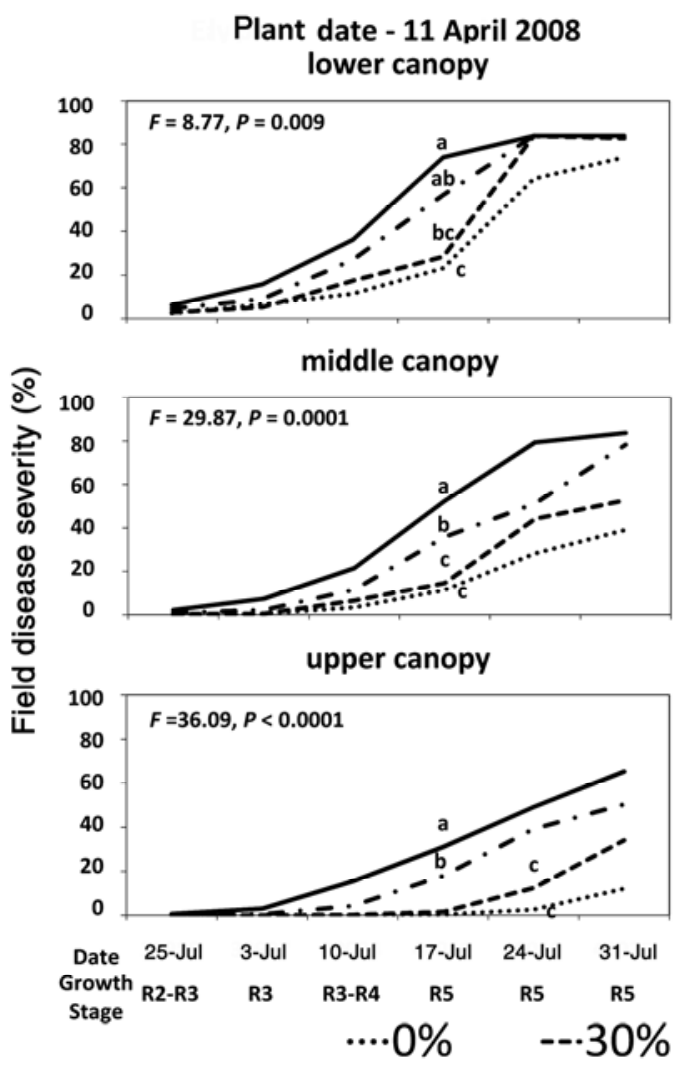

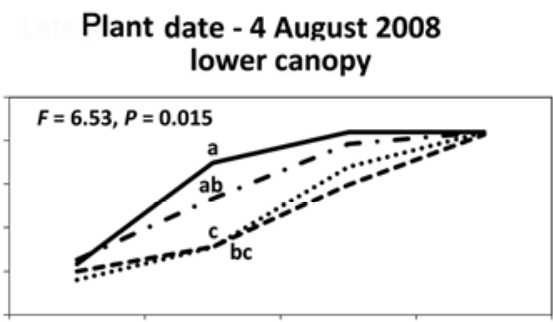

middle canopy

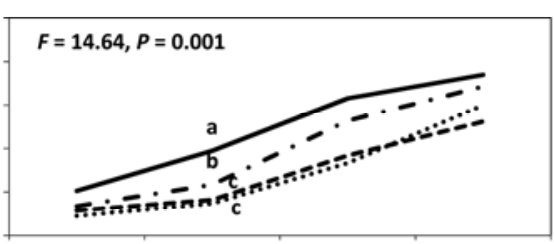

upper canopy

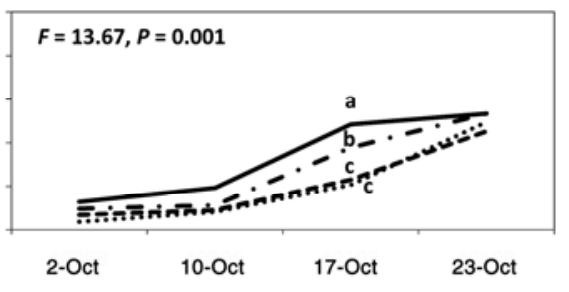

R3 R4 R4-R5 R5
Plant date - 23 Julv 2009 lower canopy

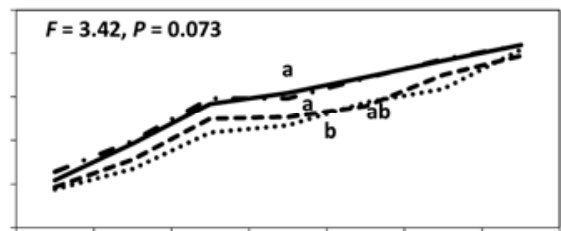

middle canopy

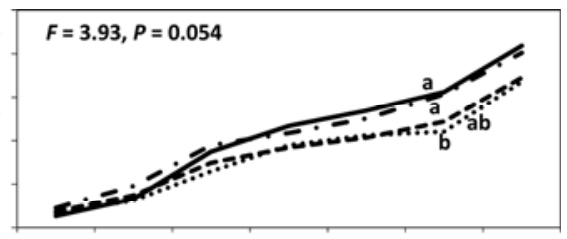

upper canopy

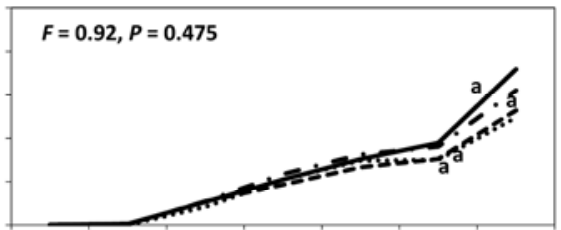

5-Sep 11-Sep 19-Sep 25-Sep 3-Oct 7-Oct 15-Oct $\begin{array}{lllllll}\text { R1-R2 } & \text { R3 } & \text { R4 } & \text { R4 } & \text { R5 } & \text { R5-R6 } & \text { R6 }\end{array}$

\section{$-.40 \% \quad-60 \%$ Shade treatment}

Fig. 5. Severity of soybean rust rated weekly under different shade treatments $(0,30,40$, and $60 \%$ shade), canopy heights (lower, middle, and upper), and planting dates. X-axis displays date and growth stage of soybean at each evaluation. Shade cloth structures were installed at vegetative growth stage V3-V4. Severity of soybean rust was based on visual assessment of symptomatic leaf area using the scale, $0=$ no disease, $1=$ up to $2.5 \%, 2=2.5$ to $5 \%, 3=5$ to $10 \%, 4=10$ to $15 \%$, $5=15$ to $25 \%, 6=25$ to $35 \%, 7=35$ to $67.5 \%$, and $8=67.5$ to $100 \%$ of the leaf area affected by soybean rust and averages were calculated by converting each rating to the midpoint of its range. Different letters on lines indicate significant differences among shade treatments based on the area under the disease progress curve (AUDPC) analyzed by least significant differences at $P \leq 0.05$. The $F$ and $P$ values from the analysis of variance of the AUDPC, with shade treatment as the main effect, are located in the upper left corner of each graph. 
radiation (UVA, UVB, and PAR) increased from 0.15 to $11.66 \mathrm{MJ}$ $\mathrm{m}^{-2}$, mortality of urediniospores increased from 2 to $91 \%$. Germination of P. pachyrhizi urediniospores was reduced by $50 \%$ at $7.5 \mathrm{MJ} \mathrm{m}^{-2}$ and $91 \%$ at $11.66 \mathrm{MJ} \mathrm{m}^{-2}$. Appressoria formation was reduced from 60 to $80 \%$ over the same range of simulated solar radiation.

\section{DISCUSSION}

The present study examined the effects of solar radiation on the progress of SBR under field and detached leaf conditions and viability of SBR urediniospores in varying light intensities under laboratory conditions. The lack of significant differences in the AUDPC across treatments in the late planting of 2009 may be attributed to greater disease pressure (Fig. 5), minimizing the effect of shade on SBR development. Furthermore, the greater differences seen in the early planting of 2008 compared with the late plantings may be attributed to increased plant height (Fig. 1) and LAI (Fig. 2) across treatments in the early planting. The increase in plant height, LAI and greater significant differences of disease severity among treatments in the early planting are most likely due to longer day length allowing solar radiation to have a

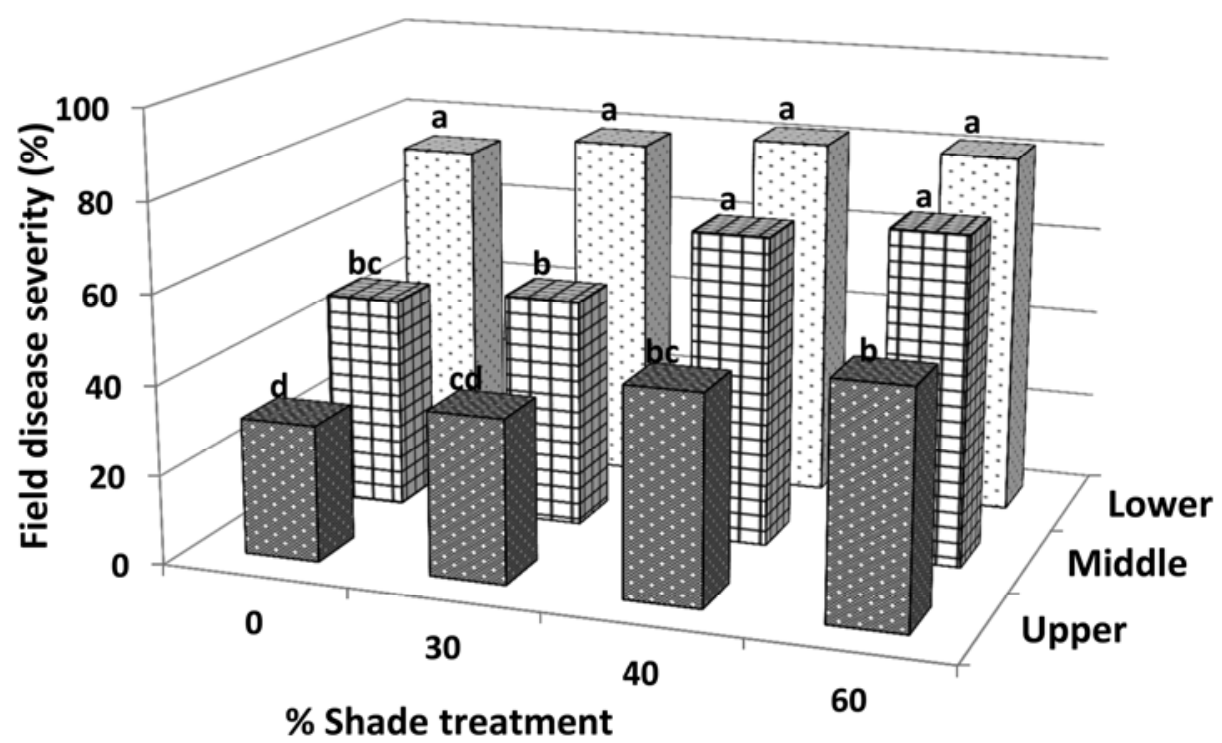

Fig. 6. Average soybean rust severity at reproductive growth stage R5 (seed development) at lower, middle, and upper soybean canopies under $0,30,40$, and $60 \%$ shade treatments in the field. Shade cloth structures were installed at vegetative growth stage V3-V4. Disease severity was assessed at ten randomly preassigned areas in each plot by visual assessment of symptomatic leaf area using the scale, $0=$ no disease, $1=$ up to $2.5 \%, 2=2.5$ to $5 \%, 3=5$ to $10 \%, 4=10$ to $15 \%, 5=$ 15 to $25 \%, 6=25$ to $35 \%, 7=35$ to $67.5 \%$, and $8=67.5$ to $100 \%$ of the leaf area affected by soybean rust and averages were calculated by converting each rating to the midpoint of its range. Different letters on the bars indicate significant differences among soybean canopy heights and shade treatments based on averages analyzed by least significant differences at $P \leq 0.05$, across treatments and canopy heights.

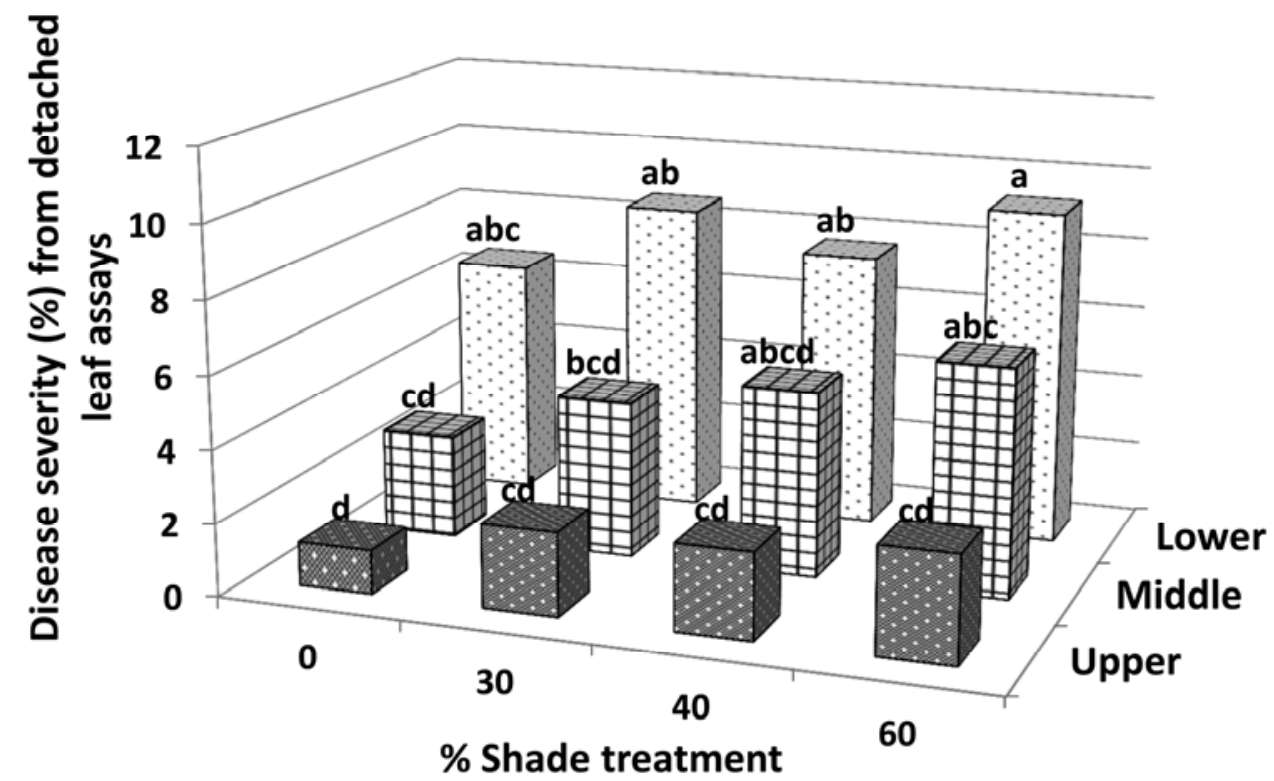

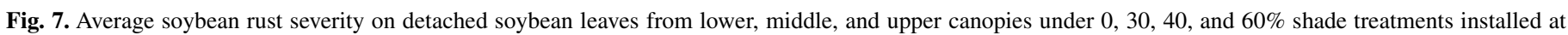

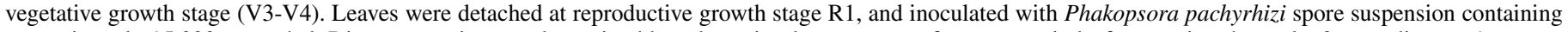

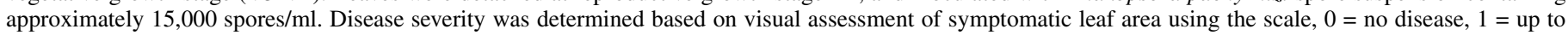

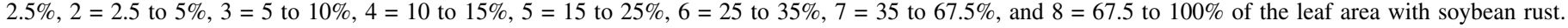

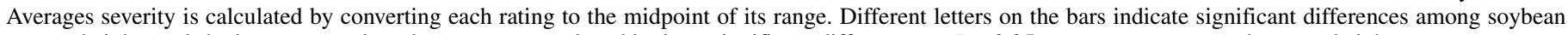
canopy heights and shade treatments based on averages analyzed by least significant differences at $P \leq 0.05$, across treatments and canopy heights. 
greater effect on plant physiology and disease development. This is further supported by the results of the ANOVA, which show that plant date and the interaction of plant date and shade treatment significantly affect disease severity. Additionally, the early planting of 2008 may have had a more uniform inoculation in the lower canopy, allowing the effect of the shade treatments to be enhanced over time and across the treatments.

Temperatures recorded throughout typical days of the growing season were within the range for SBR development. Morning and evening temperatures were within the range $\left(10\right.$ to $\left.28.5^{\circ} \mathrm{C}\right)$ for $P$. pachyrhizi germination and infection (23), and never reached above $30^{\circ} \mathrm{C}$, which can retard disease development (9). This suggests that temperature was not a limiting factor in this experiment. Temperature may have caused minor differences in disease development between nonshaded and shaded treatments, but not to differences among shaded treatments where tempera- ture was not significantly different. The high relative humidity recorded throughout typical days of the growing season was within the optimum range for SBR development and was not significantly affected by shade treatments, suggesting that relative humidity was not a limiting factor for disease development either. Similarly, Batchelor et al. (6) suggested that moisture may not be a limiting factor when they found that adjusting SBR neural network models by the inclusion of a variable for cumulative days when relative humidity exceeded $90 \%$ did not improve the accuracy of the model.

Intensity of solar radiation is more likely influencing disease development and final disease severity in the field, especially with the $60 \%$ shade treatment where the amount of UVB, UVA, and PAR was reduced to 36,34 , and $32 \%$, respectively, of the initial intensity in the nonshaded treatment (Table 1). These reduced light intensities are comparable to those in the nonshaded middle

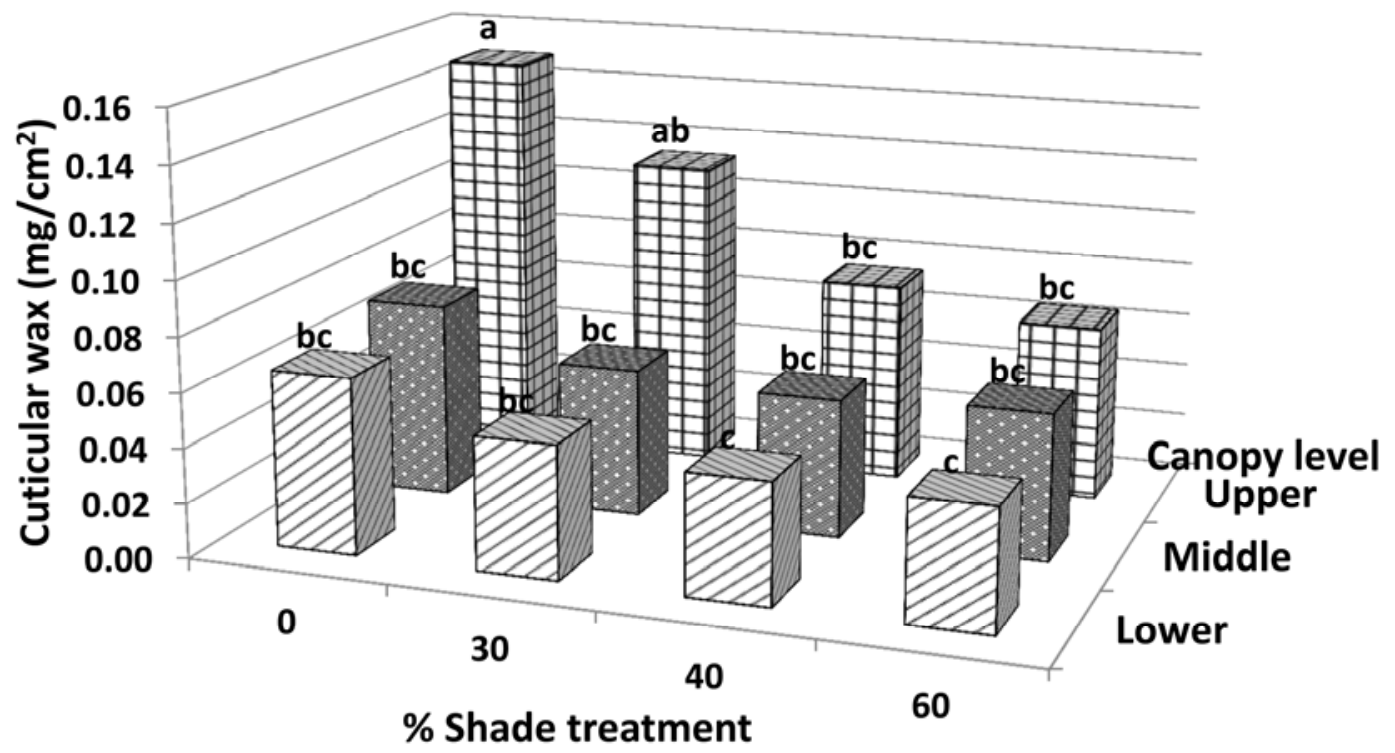

Fig. 8. Average epicuticular wax $\left(\mathrm{mg} / \mathrm{cm}^{2}\right)$ extracted from soybean leaves at reproductive growth stage, $\mathrm{R} 1$, from lower, middle, and upper canopies under 0,30 , 40, and 60\% shade treatments. Different letters on the bars indicate significant differences among soybean canopy heights and shade treatments based on averages analyzed by least significant differences at $P \leq 0.05$, across treatments and canopy heights.

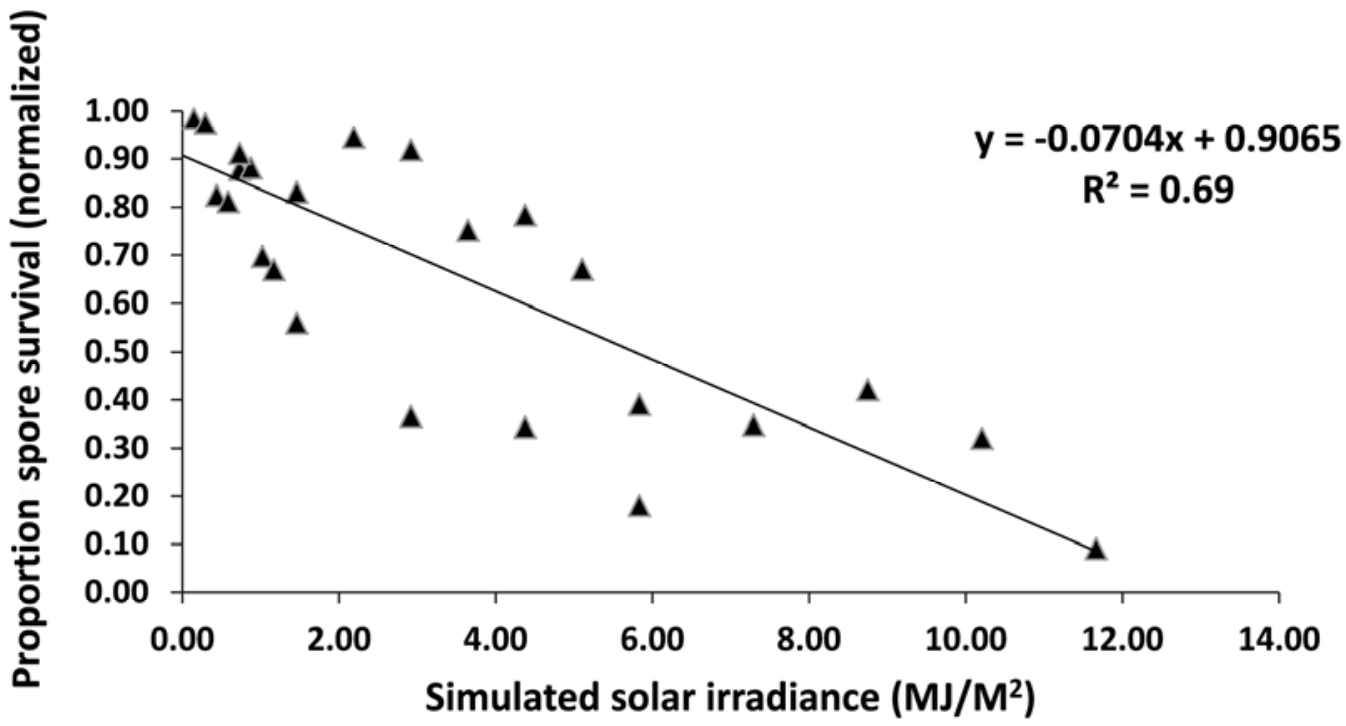

Fig. 9. Relationship between simulated solar irradiance $\left(\mathrm{MJ} \mathrm{m}^{-2}\right)$ and proportion survival of Phakopsora pachyrhizi urediniospores normalized with respect to percent survival observed in unexposed urediniospores. Spores of $P$. pachyrhizi were exposed to simulated solar radiation using a 1,000W xenon-arc lamp (model 6269, Oriel/Newport Instruments, Stratford, CT). Varying intensities of radiation (UVA+UVB ranging from 0.02 to $1.53 \mathrm{MJ}^{-2}$ ) were achieved by directing light from the lamp through either seven (simulating $90 \%$ attenuation of full sunlight) or three (simulating 50\% attenuation of full sunlight) stainless steel wire-mesh screens $\left(150 \times 150 \mathrm{~mm}^{2}\right)$ that were placed above the experimental spores or without any screens (simulation of $0 \%$ attenuation of sunlight). 
canopy (Table 2), which might be contributing to the lack of significant difference between the final disease severity of the upper canopy of the $60 \%$ shade treatment and the middle canopy of the nonshaded treatment (Fig. 6). Our data suggests the greater final disease severities in the lower canopy and shaded treatments are most likely due to difference in solar radiation and its direct and indirect effects on disease development. Similarly, Dias et al. (13) concluded that sunlight likely affects postgermination or postinfection processes in SBR contributing to final severity levels.

In addition to the direct effect of solar radiation on disease development in the field, its influence on soybean physiology may have been a contributing factor in the difference in disease severities observed in the detached leaf assays. The amount of epicuticular wax on soybean leaves could affect the pathogen's ability to infect, especially if the pathogen penetrates directly, as $P$. pachyrhizi does. In rice cultivars, infection rates by Rhizoctonia solani were negatively correlated with the amount of cuticular wax deposits on the outer sheath surface (22). It was found that the wax deposits interfered with the formation of appressorial and infection cushions of $R$. solani and when wax deposits were removed with chloroform, infection of previously resistant cultivars occurred (22). As previously reported (19), UVB radiation can affect leaf ultrastructure and anatomy, photosynthetic pigments, UVB absorbing compounds, and growth and development. In particular, UVB radiation could affect development of the epicuticular wax layer, which acts as the first line of defense against biotic and abiotic factors. The significant effect of plant date on disease severity and epicuticular wax from detached leaf assays may be explained by the decreasing day length and solar radiation occurring after the summer solstice in June impacting epicuticular wax on leaves of later planted soybean which results in greater susceptibility to SBR.

While there have been reports of environmental stresses affecting the epicuticular wax layer (19), only a few studies $(16,20,26,34)$ have reported UVB effects on epicuticular waxes of crop plants. Steinmuller and Tevini (34) reported that enhanced UVB radiation produced 23 and $28 \%$ increases in wax content on leaf areas in barley and bean, respectively. Another study with six pea genotypes differing in amounts of leaf surface waxes, showed an increase in wax content when the genotypes were exposed to UVB radiation (16). Additionally, UVB radiation can also alter the chemical composition of leaf surface waxes (34). Production of UV-absorbing compounds such as flavonoids and other phenolics that function as phytoalexins or antifungal compounds have also been attributed to UVB radiation $(20,26)$. Marta et al. (24) reported that grapevine leaves maintained at $100 \%$ sun light had high polyphenolic content and significantly lower downy mildew severity compared to leaves under shading nets. While the upper canopy epicuticular wax amounts were significantly correlated to the disease severity in the detached leaf assays more than just the amount of epicuticular wax could be contributing to reducing disease. Other components of the wax, such as chemical composition, need to be analyzed to further investigate the effect of solar radiation on the epicuticular wax layer and its interaction with $P$. pachyrhizi urediniospores.

Solar radiation could be affecting many aspects of soybean physiology with the amount of epicuticular wax being just one aspect. Similar results in which SBR was consistently more prevalent and more severe under shaded conditions (13), and instances where soybean plants kept in the dark up to $16 \mathrm{~h}$ following inoculation had greater amount of lesions even though penetration rates remained constant after $8 \mathrm{~h}$ of darkness (8), imply that sunlight affects SBR development after infection. Solar radiation may elicit defense mechanisms affecting postinfection processes. One possible defense mechanism induced by light is the production of the phytoalexin glyceollin. Greater resistance to Phytophthora megasperma f. sp. glycinea was reported in soybean seedlings incubated under light for more than $12 \mathrm{~h}$ and had a 30 times greater concentration of glyceollin as compared to seedlings incubated in the dark (36). More research needs to be conducted to further identify physiological and biochemical factors affected by solar radiation which might contribute to disease development.

Many field based and laboratory based experiments exposing fungal spores to sunlight or an artificial light source have revealed the inhibitory effect of solar radiation on germination. Isard et al. (17) reported $100 \%$ mortality of $P$. pachyrhizi urediniospores when exposed to a total solar radiation of $\geq 27.3 \mathrm{MJ} \mathrm{m}^{-2}$ and $\mathrm{UV}$ irradiance of $\geq 1.2 \mathrm{MJ} \mathrm{m}^{-2}$ over a 2-day field trial. The greater susceptibility of $P$. pachyrhizi urediniospores in the laboratory experiment as compared to the shade plot trials could be due to more stringent laboratory conditions compared with field conditions where the effect of other environmental factors influencing susceptibility of the urediniospores is likely. In other laboratory studies, Rotem et al. (30) observed $100 \%$ mortality after spores of Uromyces phaseoli and attached and detached spores of Peronospora tabacina were exposed to short wavelength radiation $\left(\mathrm{UV}_{250}\right)$ at doses between 8 and $10 \mathrm{~kJ} \mathrm{~m}^{-2}$. Similarly, Aylor and Sanogo (3) reported about $95 \%$ loss of germinability in Venturia inaequalis conidiospores with doses of $\mathrm{UV}_{254}$ of about 8.1 to $10.8 \mathrm{~kJ} \mathrm{~m}^{-2}$ under laboratory conditions and with doses of $\mathrm{D}_{\mathrm{UVB}}$ of $0.044 \mathrm{MJ} \mathrm{m}^{-2}$ under field conditions. When conidia of Aspergillus flavus and Penicillium notatum were exposed to $\mathrm{UV}_{254}$ at $0.4 \mathrm{~W} \mathrm{~m}^{-2}$ germination was inhibited (27). Consistent with other studies $(3,5)$, findings from our experiments indicate that solar radiations (UVA+UVB+PAR) influence urediniospore viability depending on duration of exposure. This could have major implications in understanding the epidemiology and spread of SBR urediniospores with respect to differential viability and hence infectivity on cloudy and/or windy days versus sunny days $(2,5)$. The probability of $P$. pachyrhizi urediniospores being viable and hence having the potential to cause infection at a given location can be reasonably projected using solar radiation data along the path of travel of the urediniospores $(17,18)$.

Results from the current study indicate that solar radiation influences the viability of $P$. pachyrhizi urediniospores, and thus, is an important factor in its survivability while being airborne. While moderate to high intensities of solar radiation (10 to $11.66 \mathrm{MJ} / \mathrm{m}^{2}$ ) substantially inhibit urediniospore germination (70 to $91 \%$ ), lower intensities (below $10 \mathrm{MJ} / \mathrm{m}^{2}$ ) do not completely inhibit urediniospore viability, and thus, mildly exposed urediniospores may still have potential to cause infection if conditions favoring rapid long-distance transport exist. However environmental factors such as the influence of cloud cover, wind etc. on solar radiation and its effect on spore viability need to be understood more clearly. Other aspects that may affect sensitivity of $P$. pachyrhizi urediniospores to solar radiation and hence warrant future investigation include: age of the urediniospores, and presence of urediniospore clumps upon release and while being airborne.

Results from field and laboratory trials support the conclusion that solar radiation influences progress of SBR caused by $P$. pachyrhizi by affecting urediniospore viability, disease development across canopy heights, and epicuticular wax content. Significant differences in disease severity in upper canopy heights in detached leaf assays correlated well with epicuticular wax values, with wax values decreasing and disease severity increasing as canopy height decreased. Solar radiation has a direct influence on urediniospore viability, as observed across canopy heights and shade treatments, was confirmed by laboratory experiments where viability of urediniospores was tested after exposure to a source of UV radiation closely simulating radiation exposures in the field. Our studies suggest while factoring in the influence of solar radiation on disease progress and severity of SBR in forecasting models, effect of its UV component on environmental conditions 
has indirect effects as well. The direct and indirect (both canopy microclimate and leaf physiology) effects of solar radiation may explain in part the observation in the field that the disease is more severe in the lower canopy.

\section{ACKNOWLEDGMENTS}

This research was supported by funds from the North Central Soybean Research Program. We thank K. O'Brien and those who helped with the construction of the shade structures and maintenance of the plots.

\section{LITERATURE CITED}

1. Asthana, A., and Tuveson, R. W. 1992. Effects of UV and phototoxins on selected fungal pathogens of citrus. Int. J. Plant Sci. 153:442-452.

2. Aylor, D. E. 1999. Biophysical scaling and the dispersal of fungal spores: Relationship to integrated pest management strategies. Agric. Forest Meteorol. 97:275-292.

3. Aylor, D. E., and Sanogo, S. 1997. Germinability of Venturia inaequalis conidia exposed to sunlight. Phytopathology 87:628-633.

4. Baker, E. A. 1974. The influence of environment on leaf wax development in Brassica oleracea var. gemmifera. New Phytol. 73:955-966.

5. Bashi, E., and Aylor, D. E. 1983. Survival of detached sporangia of Peronospora destructor and Peronospora tabacina. Phytopathology 73:1135-1139.

6. Batchelor, W. D., Yang, X. B., and Tschanz, A. T. 1997. Development of a neural network for soybean rust epidemics. Tans. ASAE 40:247-252.

7. Beattie, G. A., and Marcell, L. M. 2002. Effect of alterations in cuticular wax biosynthesis on the physicochemical properties and topography of maize leaf surfaces. Plant Cell Environ. 25:1-16.

8. Bonde, M., Melching, J., and Bromfield, K. 1976. Histology of the suscept-pathogen relationship between Glycine max and Phakopsora pachyrhizi, the cause of soybean rust. Phytopathology 66:1290-1294.

9. Casey, P. S. 1979. The epidemiology of soybean rust-Phakopsora pachyrhizi Syd. Ph.D. thesis, University of Sydney. http://hdl.handle.net/ 2123/1676

10. Clark, J. A., and Levitt, J. 1956.The basis of drought resistance in the soybean plant. Physiol. Plant 9:598-606.

11. Del Ponte, E. M., and Esker, P. D. 2008. Meteorological factors and Asian soybean rust epidemics-A systems approach and implications for risk assessment. Sci. Agric. (Piracicaba, Braz.) 65:88-97.

12. Del Ponte, E. M., Godoy, C. V., Li, X., and Yang, X. B. 2006. Predicting severity of Asian soybean rust epidemics with empirical rainfall models. Phytopathology 96:797-803.

13. Dias, A. P. S., Li, X., Harmon, P. F., Harmon, C. L., and Yang, X. B. 2011. Effects of shade intensity and duration on Asian soybean rust caused by Phakopsora pachyrhizi. Plant Dis. 95:485-489.

14. Flenet, F., Kiniry, J. R., Board, J. E., Westgate, M. E., and Reicosky, D. C. 1996. Row spacing effects on light extinction coefficients of corn, sorghum, soybean, and sunflower. Agron. J. 88:185-190.

15. Ghajar, F., Holford, O., Cother, E., and Beattie, A. 2006. Effects of ultraviolet radiation, simulated or as natural sunlight, on conidium germination and appressorium formation by fungi with potential as mycoherbistats. Biocontrol Sci. Technol. 16:451-469.

16. Gonzalez, R., Paul, N. D., Percy, L., Ambrose, M. McLaughlin, C. K., Barnes, J. D., Aresea, M., and Wellburn, A. R. 1996. Responses to ultraviolet-B radiation $(280-315 \mathrm{~nm})$ of pea (Pisum sativum) lines differing in leaf surface wax. Physiol. Plant 98:852-860.

17. Isard, S. A., Dufault, N. S., Miles, M. R., Hartman, G. L., Russo, J. M., De Wolf, E. D., and Morel, W. 2006. The effect of solar irradiance on the mortality of Phakopsora pachyrhizi urediniospores. Plant Dis. 90:941-945.

18. Isard, S. A., Gage, S. H., Comtois, P., and Russo, J. M. 2005. Principles of the atmospheric pathway for invasive species applied to soybean rust. Bioscience 55:851-861.

19. Kakani, V. G., Reddy, K. R., Zhao, D., and Sailaja, K. 2003. Field crop responses to ultraviolet-B radiation: A review. J. Agric. Forest. Meteorol. 120:191-218.

20. Keller, M., Rogiers, S. Y., and Schultz, H. R. 2003. Nitrogen and ultraviolet radiation modify grapevines' susceptibility to powdery mildew. Vitis 42:87-94.

21. Krupa, S., Bowersox, V., Claybrooke, R., Barnes, C. W., Szabo, L., Harlin, K., and Kurle, J. 2006. Introduction of Asian soybean rust urediniospores into the Midwestern United States-A case study. Plant Dis. 90:1254-1259.

22. Marchall, D. S., and Rush, M. C. 1980. Infection cushion formation on rich sheaths by Rhizoctonia solani. Phytopathology 70:947-950.

23. Marchetti, M. A., Melching, J. S., and Bromfield, K. R. 1976. The effect of temperature and dew period on germination and infection by urediospores of Phakopsora pachyrhizi. Phytopathology 66:461-463.

24. Marta, A. D., Di Stefano, V., Cerovic, Z. G., Agati, G., and Orlandini, S. 2008. Solar radiation affects grapevine susceptibility to Plasmopara viticola. Sci. Agric. 65:65-70.

25. McWilliams, D. A., Berglund, D. R., and Endres, G. J. 2004. Soybean Growth and Management Quick Guide. Online Publication. NDSU Agriculture and University Extension. A-1174.

26. Modolo, L. V., Cunha, F. Q., Braga, M. R., and Salgado, I. 2002. Nitric oxide synthase-mediated phytoalexin accumulation in soybean cotyledons in response to the Diaporthe phaseolorum f. sp. meridionalis elicitor. Plant Physiol. 130:1288-1297.

27. Osman, M., El Sayed, Y. A. H., Mohamed, Y. A. H., and Abo-Zeid, A. M. 1989. Effect of ultraviolet irradiation on germination and growth in Aspergillus flavus and Penicillium notatum. Mycol. Res. 92:293-296.

28. Pan, Z., Yang, X. B., Pivonia, S., Xue, L., Pasken, R., and Roads, J. 2006. Long-term prediction of soybean rust entry into the continental United States. Plant Dis. 90:840-846.

29. Rotem, J., and Aust, H. J. 1991. The effect of ultraviolet and solar radiation and temperature on survival of fungal propagules. J. Phytopathol. 133:76-84.

30. Rotem, J., Wooding, B., and Aulor, D. E. 1985. The role of solar radiation, especially ultraviolet, in the mortality of fungal spores. Phytopathology 75:510-514.

31. Schuerger, A. C., Mancinelli, R. L., Kern, R. G., Rothschild, L. J., and McKay, C P. 2003. Survival of endospores of Bacillus subtilis on spacecraft surfaces under simulated martian environments: Implications for the forward contamination of Mars. Icarus 165:253-276

32. Skoss, J. D. 1955. Structure and composition of the plant cuticle in relation to environmental factors and permeability. Bot. Gaz. 117:55-72.

33. Sojka, R. E., and Parsons, J. E. 1983. Soybean water and canopy microclimate relationships of four row spacings. Agron. J. 75:961-968.

34. Steinmuller, D., and Tevini, M. 1985. Action of ultraviolet radiation (UVB) upon cuticular waxes in some crop plants. Planta 164:557-564.

35. Vidhyasekaran, P. 2004. Concise Encyclopedia of Plant Pathology. Food Products Press and The Haworth Reference Press, Binghamton, NY.

36. Ward, E. W. B., and Buzzell, R. I. 1983. Influence of light, temperature and wounding on the expression of soybean genes for resistance to Phytophthora megasperma f. sp. glycinea. Physiol. Plant Pathol. 23:401409.

37. Welles, J. M., and Cohen, S. 1996. Canopy structure measuring by gap fraction analysis using commercial instrumentation. J. Exp. Bot. 47:13351342.

38. Young, H. M., Marois, J. J., Wright, D. L., Narváez, D. F., and O’Brien, K. 2011. Epidemiology of soybean rust in soybean sentinel plots in Florida. Plant Dis. 95:744-750.

39. Zavala, J. A., Scopel, A. L., and Ballaré, C. L. 2001. Effects of ambient UV-B radiation on soybean crops: Impact on leaf herbivory by Anticarsia gemmatalis. Plant Ecol. 156:121-130. 